\title{
Mediating Role of Psychological Capital in Explaining the Relationship between Job Stressors and Burnout among Employees of Hamadan University of Medical Sciences
}

\author{
Bahram Tahmacbi $^{1}$, Mehdi Zare Bahramabadi* ${ }^{*}$, Mahshid Izadi ${ }^{3}$, Hamide Abdolhoseini ${ }^{4}(\mathbb{D})$ \\ 1 PhD Candidate, Department of Education Science and Counseling, Faculty of Psychology, Central Tehran Branch, Islamic \\ Azad University, Tehran, Iran \\ 2 Institute for Research and Development in the Humanities, SAMT \\ 3 Professor Assistant Education Department, Psychology Faculty, Islamic Azad University-Central Branch, Tehran, Iran \\ ${ }^{4} \mathrm{PhD}$ in Career Counseling, University of Isfahan, Isfahan, Iran
}

*Corresponding author:

Mehdi Zare Bahramabadi, Institute for

Research and Development in the

Humanities, SAMT

Tel: 9188123623

Email:mz.bahramabadi@gmail.com

Received: 01 Mar. 2020

Accepted: 30 Apr. 2020

ePublished: 01 Aug. 2020

\begin{abstract}
Background and Objective: Job stress is recognized as one of the leading causes of burnout. Psychological capital is another critical factor which is directly linked to burnout. Therefore, the present study aimed to model burnout based on job stressors with the mediating role of psychological capital among employees of Hamadan University of Medical Sciences.

Materials and Methods: This cross-sectional descriptive-analytical study was conducted on 378 non-faculty members of Hamadan University of Medical Sciences in 2019. The data were collected using the Maslach Burnout Inventory, Health, and Safety Executive (HSE) Stress Questionnaire, and the Psychological Capital Questionnaire developed by Luthans. To evaluate the relationship among variables, Structural Equation Modeling (SEM) was used in AMOS software (version 24).

Results: The components of job stressors had a positive and significant correlation with all three components of burnout $(\mathrm{P}<0.05)$. The measurement model with the collected data had an acceptable fitness $(x 2 / d f=3.56, C F I=0.932, A G F I=0.870, G F I=0.915$, and Root Mean Square Error of Approximation (RMSEA) $=0.081$ ). Psychological capital positively and significantly mediated the relationship between job stressors and burnout in employees of the University of Medical Sciences $(\mathrm{P}<0.05)$. The sum of squares of multiple correlations for burnout variable was obtained at 0.52 . This finding indicates that job stressors and psychological capital explain $52 \%$ of burnout variance.

Conclusion: Due to the harmful effects of burnout on employees, it is suggested that authorities take measures to reduce stressors, such as psychological and physical needs of the workplace, lack of support, lack of job security, and psychological capital.

Keywords: Burnout, Job stress, Psychological capital
\end{abstract}

\section{Background}

Human resources as the most crucial assets of any organization or institution perform a peculiar role in the accomplishment of organizational goals. One of the characteristics of a healthy organization is the value it places on the physical and mental health of its employees for the benefit of production and productivity. nonetheless, numerous jobs often bring employees under psychological pressure, which leads to burnout in the long run. Job stress is recognized as one of the leading causes of burnout. In recent years, stress has increased so dramatically that job stress is called the Black Plague or modern Plague in the present era [1]. The exposure of employees to stress in the workplace is one of these notable changes [2]. Stress as one of the factors affecting employee performance and burnout in organizations has put the health of many employees at risk and emerged as a common and costly issue in the workplace. [3]. Stress derives from the interaction with the environment and occurs at the presence of a mismatch between situational pressures and the resources a person possesses [4]. Job stress occurs when the expectations of the individual are more than his/her powers and abilities [5]. Organizational changes, amount of salary, excessive responsibilities, as well as decreasing or increasing human resources, are among the major sources of job stress. [6]. Based on the related studies, job stress has many negative consequences for employees, such as burnout, job dissatisfaction, and career change. Poor job performance and improper physical conditions, such as hypertension, depression, anxiety, sleep problems, and taking drugs and medications, are 
among the notable effects of workplace stress. Moreover, emotional exhaustion, depersonalization, and reduced personal accomplishment are other negative outcomes of job stress. [7-10].

Psychological capital is another key factor which is directly correlated with burnout. [11]. The first component of psychological capital is self-efficacy, which involves the confidence of individuals in their abilities to perform the tasks and challenges they face. [12]. These structures have a high potential for change, and individuals can provide the grounds for their growth by various methods in the event of appropriate mental and situational conditions, [13]. In this regard, numerous studies have pointed to a significant and considerable relationship between psychological capital and burnout. Therefore, burnout, which is mainly the result of pressures and workplace stress, can be reduced by increasing the psychological capital [14-17].

The literature review indicated that the relationship between these structures and burnout has been separately examined and studied. Nevertheless, no study has yet been conducted on the relationship of these structures in a harmonious and unified manner in the form of a model. The issue of burnout assumes great importance among employees as an influential group of society and the few studies in this field in Iranian society, especially on the employees of Universities of Medical Sciences. Therefore, the results of this study can affect the improvement of micro, macro, educational, social, cultural, and health planning, which in turn, results in the enhancement of community health.

\section{Objectives}

The present study aimed to model burnout based on job stressors with the mediating role of psychological capital among employees of Hamedan University of Medical Sciences.

\section{Materials and Methods}

This descriptive-analytical cross-sectional study was conducted in 2019. The statistical population consisted of non-faculty employees of Hamedan University of Medical Sciences schools (campus). The sampling method in this study was census so that all employees were enrolled. Data were collected using the Maslach Burnout Inventory (MBI), Health and Safety Executive (HSE) Stress Questionnaire, and the Luthans Psychological Capital Questionnaire (PCQ).

\section{Maslach Burnout Inventory (MBI)}

This questionnaire is an introspective psychological inventory consisting of 22 items pertaining to occupational burnout developed by Maslach in 1985. The MBI measures three dimensions of burnout: emotional exhaustion (9 items), depersonalization (5 items), and personal accomplishment (8 items). Accordingly, in the overall score of burnout, the score below 18 is regarded as no burnout, 19-53 as mild burnout, 54-89 moderate burnout, and 90-108 as severe burnout [18-20]. The validity and reliability of this questionnaire were confirmed in the study carried out by Afshani et al., and the Cronbach's alpha was reported to be 0.88 [21].

Health and Safety Executive (HSE) Stress Questionnaire

Health and Safety Executive (HSE) Stress Questionnaire was constructed by the British Health and Safety Executive (HSE) in 1990 to measure the job stress of workers and employees [22]. The questionnaire consists of 35 questions and 7 domains (demand, control, authorities' support, coworkers' support, relation, role, and change), and its reliability and validity have been confirmed [23]. In Iran, the reliability and validity of this questionnaire were assessed by Azad Marzabadi et al. rendering Cronbach's alpha coefficient of 0.78 and a correlation coefficient of 0.65 [23].

Luthans Psychological Capital Questionnaire (PCQ) This questionnaire was designed by Luthans et al. in 2007 to measure psychological capital. It contains 24 items and evaluates 4 components of hope, resilience, optimism, and self-efficacy (6 items in each component). [11]. Moreover, in Iran, Hashemi Nosrat Abad et al. (2011) reported a reliability coefficient of 0.82 using Cronbach's alpha method [24].

To obtain the needed data, the necessary permissions were obtained, and the questionnaires were administered to the employees who were willing to participate in coordination with the officials from different departments of the university. Thereafter, they were given enough time to answer the questions. Finally, after the completion of all questionnaires, the data were entered into the relevant software and analyzed. Structural Equation Modeling (SEM) was used to explore the causal relationships among latent variables of job stress, burnout, and psychological capital. In the measurement model of the present study, it was assumed that the latent variable of job stressors by the indicators of role, relation, authorities' support, co-workers' support, control, demand, and change, the latent variable of psychological capital by the indicators of selfefficacy, hope, resilience, and optimism and the 
latent variable of burnout by the indicators of emotional exhaustion, depersonalization, and personal accomplishment are measured. In this study, AMOS software (version 24) was used for data analysis, model estimation, model fit test, and causal power; moreover, SPSS software (version 18) was utilized to describe the data.

\section{Results}

The present study was conducted on 378 participants (182 males and 203 females) with the mean age of $8.85 \pm 38.93$. The job scope of $152(39.3 \%)$ subjects was administrative/financial, 67 (17.3\%) health/ medical, 35 (9\%) technical-engineering, 57 (14.7\%) services, $46(11.9 \%)$ cultural/educational, and 27 $(7.8 \%)$ of the participants were in other areas.

As presented in Table 1, the components of role and control of job stressors were positively correlated with all three components (i.e., emotional exhaustion, depersonalization, and personal accomplishment) of burnout at the level of 0.01 . The components of relation, co-workers' support, and changes in job stressors were positively correlated with the components of emotional exhaustion and depersonalization of burnout at the level of 0.01; moreover, they were positively correlated with the component of personal accomplishment at the level of 0.05 .

Table 2 represents the fit indices of the initial measurement model and the modified models. The results indicated that the fit indices obtained from confirmatory factor analysis do not support the fitting of the initial measurement model with the collected data $(\mathrm{x} 2 / \mathrm{df}=4.76, \quad \mathrm{CFI}=0.099$, AGFI=0.837, GFI=0.886, and RMSEA=0.099). As a result, the measurement model was obtained in five stages by creating a covariance between the indicators of authorities' support, co-workers' support (first stage), relation and demand (second stage), depersonalization and personal accomplishment (third stage), and demand and change (fourth stage) and finally the fit indices. It demonstrated that the measurement model had an acceptable fit with the collected data $(\mathrm{x} 2 / \mathrm{df}=3.56$, $\mathrm{CFI}=0.932, \quad \mathrm{AGFI}=0.870, \quad \mathrm{GFI}=0.915, \quad$ and RMSEA $=0.081$ ).

Table 3 illustrates the total, direct, and indirect path coefficients among the research variables in the structural model. As illustrated in Table 3, the total path coefficient between job stressors and burnout was positive and significant at the level of 0.01 $(\beta=0.523 ; \mathrm{P}<0.01)$. Moreover, the path coefficient between psychological capital and burnout was negative and significant at the level of $0.01 \quad \beta=$ $0.581 ; \mathrm{P}<0.01)$. Finally, the indirect path coefficient between job stressors and burnout was positive $(\beta=0.013 ; P<0.01)$ and significant at the level of 0.01 . Accordingly, the results of the present study

Table 1. Correlation coefficients among research variables $(n=378)$

\begin{tabular}{|c|c|c|c|c|c|c|c|c|c|c|c|c|c|c|}
\hline $\begin{array}{l}\text { Research } \\
\text { Variables }\end{array}$ & 1 & 2 & 3 & 4 & 5 & 6 & 7 & 8 & 9 & 10 & 11 & 12 & 13 & 14 \\
\hline $\begin{array}{l}\text { 1. Job Stressors- } \\
\text { Role }\end{array}$ & - & & & & & & & & & & & & & \\
\hline $\begin{array}{l}\text { 2. Job Stressors- } \\
\text { Relation }\end{array}$ & $0.45 * *$ & - & & & & & & & & & & & & \\
\hline $\begin{array}{l}\text { 3. Job Stressors- } \\
\text { Authorities' } \\
\text { Support }\end{array}$ & $0.44 * *$ & $0.49 * *$ & - & & & & & & & & & & & \\
\hline $\begin{array}{l}\text { 4. Job Stressors- } \\
\text { Coworkers' } \\
\text { Support }\end{array}$ & $0.36^{* *}$ & $0.46 * *$ & $0.68^{* *}$ & - & & & & & & & & & & \\
\hline $\begin{array}{l}\text { 5. Job Stressors- } \\
\text { Control }\end{array}$ & $0.33^{* *}$ & $0.22 * *$ & $0.40^{* *}$ & $0.37 * *$ & - & & & & & & & & & \\
\hline $\begin{array}{l}\text { 6. Job Stressors- } \\
\text { Demand }\end{array}$ & $0.22 * *$ & $0.48 * *$ & $0.31 * *$ & $0.34 * *$ & $0.31 * *$ & - & & & & & & & & \\
\hline $\begin{array}{l}\text { 7. Job Stressors- } \\
\text { Change }\end{array}$ & $0.47 * *$ & $0.45 * *$ & $0.65 * *$ & $0.55^{* *}$ & $0.44^{* *}$ & $0.47 * *$ & - & & & & & & & \\
\hline $\begin{array}{l}\text { 8. Psychological } \\
\text { capital- Self- } \\
\text { efficacy }\end{array}$ & $-0.43 * *$ & $-0.21 * *$ & $-0.19 * *$ & $-0.28 * *$ & $-0.30 *$ & $-0.15^{* *}$ & $-0.35 * *$ & - & & & & & & \\
\hline $\begin{array}{l}\text { 9. Psychological } \\
\text { capital- Hope }\end{array}$ & $-0.40 * *$ & $-0.22 * *$ & $-0.25 * *$ & $-0.24 * *$ & $-0.32 * *$ & $-0.13 *$ & $-0.38 * *$ & $0.72 * *$ & - & & & & & \\
\hline $\begin{array}{l}\text { 10. Psychological } \\
\text { capital- Resilience }\end{array}$ & $-0.26 * *$ & -0.09 & $-0.20^{* *}$ & $-0.18^{* *}$ & $-0.25 * *$ & -0.05 & $-0.32 * *$ & $0.55^{* *}$ & $0.63 * *$ & - & & & & \\
\hline $\begin{array}{l}\text { 11. Psychological } \\
\text { capital- Optimism }\end{array}$ & $-0.37^{* *}$ & $-0.26^{* *}$ & $-0.27 * *$ & $-0.30 * *$ & $-0.28 * *$ & $-0.16^{* *}$ & $-0.38 * *$ & $0.65 * *$ & $0.75 * *$ & $0.62 * *$ & - & & & \\
\hline $\begin{array}{l}\text { 12. Burnout- } \\
\text { Emotional } \\
\text { Exhaustion }\end{array}$ & $0.36 * *$ & $0.41 * *$ & $0.27 * *$ & $0.30 * *$ & $0.31 * *$ & $0.41 * *$ & $0.38 * *$ & $-0.43^{* *}$ & $-0.46^{* *}$ & $-0.37 * *$ & $-0.52 * *$ & - & & \\
\hline $\begin{array}{l}\text { 13. Burnout- } \\
\text { Depersonalization }\end{array}$ & $0.390 * *$ & $0.30 * *$ & $0.16^{* *}$ & $0.21 * *$ & $0.15^{* *}$ & $0.19 * *$ & $0.27 * *$ & $-0.52 * *$ & $-0.48^{* *}$ & $-0.33^{* *}$ & $-0.50^{* *}$ & $0.62 * *$ & - & \\
\hline $\begin{array}{l}\text { 14. Burnout- } \\
\text { Personal } \\
\text { Accomplishment }\end{array}$ & $0.17 * *$ & $0.13 *$ & 0.02 & $0.11 *$ & 0.07 & $0.16 * *$ & $0.11 *$ & $-0.31^{* *}$ & $-0.22 * *$ & $-0.23 * *$ & $-0.27^{* *}$ & $0.44^{* *}$ & $0.56 * *$ & - \\
\hline Mean & 8.74 & 9.65 & 12.71 & 9.73 & 16.18 & 23.31 & 7.84 & 27.74 & 25.94 & 23.47 & 26.56 & 22.85 & 9.36 & 24.26 \\
\hline $\begin{array}{l}\text { Standard } \\
\text { Deviation }\end{array}$ & 3.87 & 3.98 & 4.48 & 3.45 & 4.41 & 5.10 & 2.73 & 5.65 & 5.99 & 5.38 & 5.72 & 9.72 & 5.34 & 7.93 \\
\hline
\end{tabular}


Table 2. Fit indices of the imitial measurement model and modified models $(n=378$ )

\begin{tabular}{|c|c|c|c|c|c|c|}
\hline \multirow[b]{2}{*}{ Fit indices } & \multirow{2}{*}{$\begin{array}{c}\text { Initial } \\
\text { Measurement } \\
\text { Model }\end{array}$} & \multicolumn{4}{|c|}{ Modified Measurement Model } & \multirow{2}{*}{$\begin{array}{l}\text { Cut-off } \\
\text { Point }\end{array}$} \\
\hline & & $\begin{array}{c}\text { First } \\
\text { Modification }\end{array}$ & $\begin{array}{c}\text { Second } \\
\text { Modification }\end{array}$ & $\begin{array}{c}\text { Third } \\
\text { Modification }\end{array}$ & $\begin{array}{c}\text { Fourth } \\
\text { Modification }\end{array}$ & \\
\hline Chi-square & 352.24 & 314.63 & 295.21 & 269.79 & 249.18 & - \\
\hline Model degrees of freedom & 74 & 73 & 72 & 71 & 70 & - \\
\hline$x 2 / d f$ & 4.76 & 4.31 & 4.10 & 3.80 & 3.56 & Less than 3 \\
\hline GFI & 0.886 & 0.897 & 0.902 & 0.911 & 0.915 & $0.90>$ \\
\hline AGFI & 0.837 & 0.850 & 0.855 & 0.866 & 0.870 & $0.850>$ \\
\hline $\mathrm{CFI}$ & 0.894 & 0.908 & 0.915 & 0.925 & 0.932 & $0.90>$ \\
\hline RMSEA & 0.099 & 0.093 & 0.090 & 0.085 & 0.081 & $0.08<$ \\
\hline
\end{tabular}

RMSEA: Root Mean Square Error of Approximation

Table 3. Total, direct, and indirect path coefficients among the research variables in the research model

\begin{tabular}{lcccc}
\hline Path Coefficient & b & S.E & B & Sig \\
\hline Direct path coefficient of job stressors $\rightarrow$ burnout & 0.726 & 0.280 & 0.222 & 0.005 \\
Path coefficient of psychological capital $\rightarrow$ burnout & -1.030 & 0.130 & -0.581 & 0.001 \\
Path coefficient of job stressors $\rightarrow$ psychological capital & -0.956 & 0.127 & -0.518 & 0.001 \\
Indirect path coefficient of job stressors $\rightarrow$ burnout & 0.984 & 0.169 & 0.301 & 0.001 \\
Total path coefficient of job stressors $\rightarrow$ burnout & 1.710 & 0.266 & 0.523 & 0.001 \\
\hline
\end{tabular}

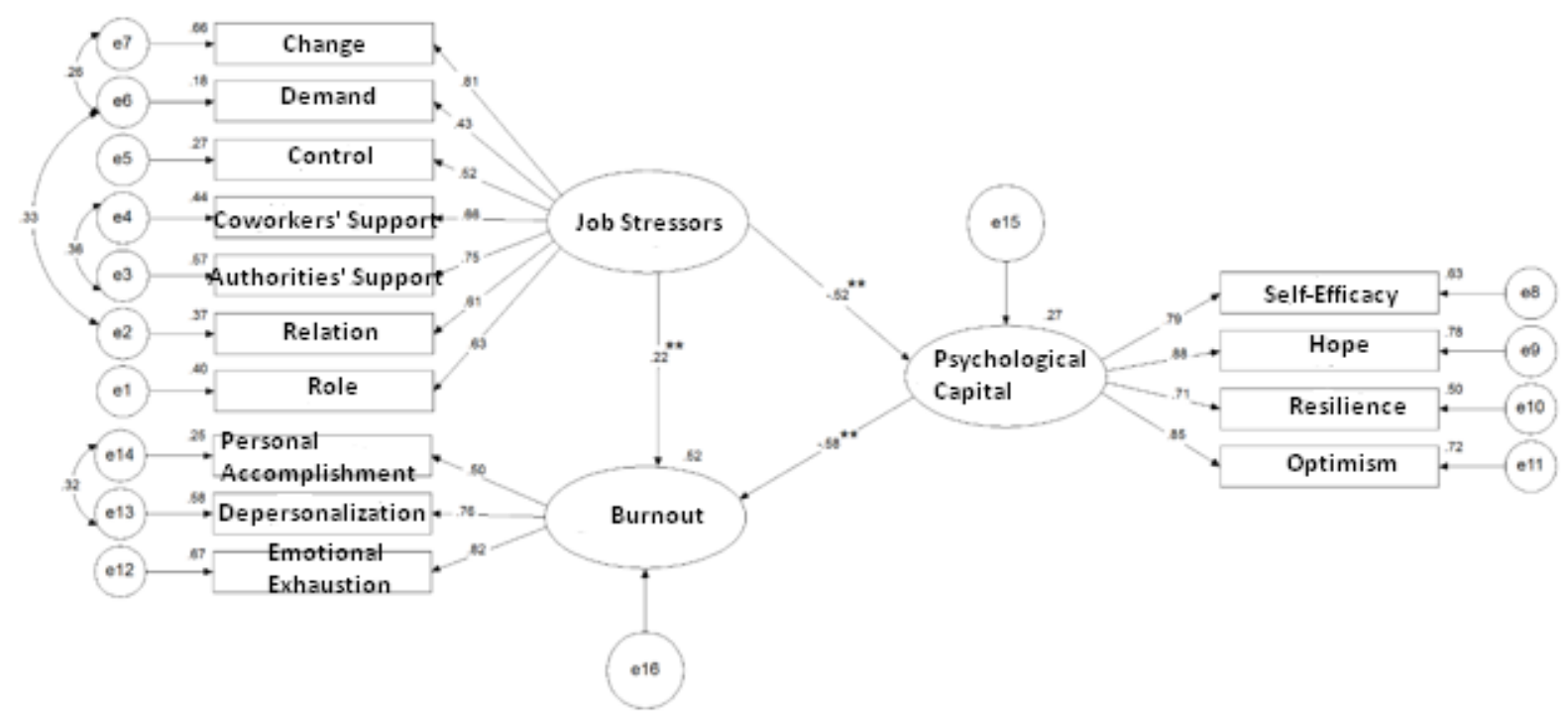

Figure 1. Overall model of research and path coefficients of variables based on standard scores

indicated that psychological capital positively and significantly mediates the relationship between job stressors and burnout among employees of the University of Medical Sciences.

Figure 1 illustrates the research model in explaining the relationships of burnout with job stressors and psychological capital In the model presented in Figure 1, it can be observed that the sum of squares of multiple correlations for the variable of burnout was obtained at 0.52 . This finding indicates that job stressors and psychological capital explain $52 \%$ of the burnout variance together.

\section{Discussion}

As evidenced by the results of the current study, the components of job stressors had a positive and significant correlation with all three components of burnout-that is to say, burnout will increase by increasing job stressors. These findings are consistent with the results of the studies conducted by Heydari et al., Zarger et al., Hajlou et al., Rahmani et al., Shakerinia et al., Abdi et al., Watson et al., Jamal et al., and Gholami et al. $[10,25-33]$.

Thereafter, after ensuring the acceptable fitness of the measurement model with the gathered data, the structural model fitting was evaluated. In the structural model, it was assumed that job stressors predicted burnout both directly and through the mediating role of psychological capital. As expected and considering the equality of the number of observed variables, latent variables, and degrees of 
freedom in measurement and structural models, similar fitness indices were obtained for the structural model. It was concluded that the structural model, like the measurement model, has fitness with the collected data.

In their study, Golmohammadian et al. (2016) investigated the role of psychological capital in the prediction of job burnout among primary school teachers at special schools of Kermanshah. The results of the mentioned study pointed to a significant relationship between the dimensions of psychological capital and the dimensions of burnout. The total score of psychological capital significantly predicted humility and generosity, depersonalization, and personal accomplishment. These results highlighted the role and importance of organizational psychological capital in the prediction of burnout among teachers. In 2016, Ahmadpanah et al conducted a study on the relationship between burnout and personality type among Iranian general practitioners $(\mathrm{n}=100)$ and found a significant relationship between personality type and burnout [33]. In the same direction, Alipour et al. 2013carried out a study to evaluate the effectiveness of Luthans psychological capital intervention program on burnout. The mentioned study assessed 60 experts working in Iran Khodro Diesel Company who were randomly placed into two experimental and control groups $(\mathrm{n}=30$ in each group). The results of their analysis indicated that the mean score of burnout and subscales which differed between the two groups in the pre-test showed a significant decrease after the intervention in the experimental group in the total score of burnout and the subscales of emotional exhaustion and depersonalization. However, despite a significant reduction, a significant difference was not observed in the subscale of lack of efficacy. As a matter of fact, it can be argued that the intervention program of Luthan's psychological capital affects the reduction of burnout, especially the subscales of emotional exhaustion and depersonalization. Therefore, it can be an excellent executive strategy to reduce burnout. Luthans et al. (2010) showed that the effective level of feelings of incompetence can be reduced, and efficiency can be increased with the help of this model. The result revealed that the growth of psychological capital can positively affect the performance of employees. Nonetheless, the ineffectiveness of this intervention method in efficacy can be ascribed to the fact that the impact initially becomes evident on the components of emotional exhaustion and depersonalization, while the effect on the efficacy component takes time to emerge. The results of studies conducted by Golmohammadian et al.,
Alipour et al., as well as Luthans et al. are in accordance with the findings of the present study $[14,34,35]$.

In the current study, job stressors predicted burnout both directly and through the mediating role of psychological capital. Nevertheless, Khajehpour et al., in their study conducted in 2015 examined the direct effect of psychological capital on turnover intention, burnout, and job performance, as well as the indirect effect of this relationship through job stress. For this purpose, they evaluated 182 employees of Gotvand Water and Power Company through Structural Equation Modeling (SEM). The results of the mentioned study indicated the effect of psychological capital on turnover intention, burnout, and job performance, the effect of job stress on turnover intention, burnout, and job performance, as well as the indirect effect of psychological capital on turnover intention and burnout through job stress. Unlike the present study, psychological capital predicted burnout both directly and through the mediating role of job stress. This discrepancy between the current research and the study by Khajehpour et al. can be attributed to their different objectives [36].

Among the notable limitations of this study is the study population, including non-faculty employees of Hamadan University of Medical Sciences. Appropriate comparisons can be made between faculty and non-faculty staff by the addition of faculty employees to the target population of this study.

\section{Conclusions}

As evidenced by the results of the current study, job stressors and psychological capital are the main determinants of job burnout. Therefore, due to the harmful effects of burnout on staff, it is suggested that authorities reduce stressors such as psychological and physical needs of the workplace, lack of support, job insecurity, as well as psychological capital.

\section{Acknowledgments}

The current article was extracted from a Ph.D. dissertation carried out at the Faculty of Psychology and Educational Sciences, Islamic Azad University, Central Tehran Branch. Our deepest appreciation goes to all the employees who participated in this research project.

\section{Authors' contributions}

All authors participated in the initial study of determining the subject, implementing the processes, analyzing the data, and writing the final report.

\section{Conflicts of Interest}

The authors declare that they have no conflict of interest regarding the publication of this article. 


\section{References}

1. Karchani M, Ebrahimi A. The survey of occupational stress, effective factors and relation it with fields human errors on staff of hospital. Iranian Safety Science and Technology Journal. 2015; 2(4):49-58.

2. Gerber $M$, Pühse U. "Don't crack under pressure!"--Do leisure time physical activity and self-esteem moderate the relationship between school-based stress and psychosomatic complaints? Journal of Psychosomatic Research. 2008; 65(4):363-9. [DOI:10.1016/j.jpsychores.2008.06.012] [PMID]

3. Hoboubi N, Choobineh A, Ghanavati FK, Keshavarzi S, Hosseini AA. The impact of job stress and job satisfaction on workforce productivity in an Iranian petrochemical industry. Safety and Health at Work. 2017; 8(1):67-71. [DOI:10.1016/j.shaw.2016.07.002] [PMID] [PMCID]

4. Seaward BL. Managing stress. Massachusetts: Jones \& Bartlett Learning; 2017.

5. Mesler R, Capobianco M. Psychosocial factors associated with job stress. Stress News. 2001; 13(4):22-4.

6. Lambert EG, Qureshi H, Frank J, Klahm C, Smith B. Job stress, job involvement, job satisfaction, and organizational commitment and their associations with job burnout among Indian police officers: a research note. Journal of Police and Criminal Psychology. 2018; 33(2):85-99. [DOI:10.1007/ s11896-017-9236-y]

7. Quick JC, Henderson DF. Occupational stress: preventing suffering, enhancing wellbeing. International Journal of Environmental Research and Public Health. 2016; 13(5):459. [DOI:10.3390/ijerph13050459] [PMID] [PMCID]

8. Farahani SB, Fotovat B, Abadzadeh P, Hemati A. Study of the role of work ethic on job stress and job burnout (Case Study: Teachers of Physical Education in Tehran Secondary Schools). Journal of Organizational Behavior Management Studies in Sport. 2018; 5(1):43-51.

9. Garrosa E, Rainho C, Moreno-Jimenez B, Monteiro MJ. The relationship between job stressors, hardy personality, coping resources and burnout in a sample of nurses: a correlational study at two time points. International Journal of Nursing Studies. 2010; 47(2):205-15. [DOl:10.1016/j.ijnurstu.2009. 05.014] [PMID]

10. Zargar Balaye Jame S, Daneshvar A. The relationship between job burnout and its dimensions with job stress in Isfahan University of Medical Sciences in 2018. Journal of Hospital. 2018; 17(3):87-99.

11. Luthans F, Avolio BJ, Avey JB, Norman SM. Positive psychological capital: Measurement and relationship with performance and satisfaction. Personnel Psychology. 2007; 60(3):541-72. [DOI:10.1111/j.1744-6570.2007.00083.x]

12. Görgens-Ekermans G, Herbert M. Psychological capital: internal and external validity of the psychological capital questionnaire (PCQ-24) on a South African sample. SA Journal of Industrial Psychology. 2013; 39(2):1-12.

13. Luthans F, Norman SM, Avolio BJ, Avey JB. The mediating role of psychological capital in the supportive organizational climate-employee performance relationship. Journal of Organizational Behavior: The International Journal of Industrial, Occupational and Organizational Psychology and Behavior. 2008; 29(2):219-38. [DOI:10.1002/ job.507]

14. Alipour A, Sarami Forushani GR, Agha Alikhani AM, Akhundi N. Evaluation of the effectiveness of psychological capital intervention of luthans on job burnout in the experts working in Iran Khodro Diesel company. Occupational Medicine Quarterly Journal. 2013; 5(3):30-41.

15. Hansen A, Buitendach $\mathrm{H}$, Kanengoni $H$. Psychological capital, subjective well-being, burnout and job satisfaction amongst educators in the Umlazi region in South Africa. SA Journal of Human Resource Management. 2015; 13(1):1-9. [DOI:10.4102/sajhrm.v13i1.621]

16. Leon-Perez IM Antino $M$, Leon-Rubio IM. The role of psychological capital and intragroup conflict on employees' burnout and quality of service: a multilevel approach.
Frontiers in Psychology. 2016; 7:1755. [DOI:10.3389/fpsyg. 2016.01755] [PMID] [PMCID]

17. Li X, Kan D, Liu L, Shi M, Wang Y, Yang X, et al. The mediating role of psychological capital on the association between occupational stress and job burnout among bank employees in China. International Journal of Environmental Research and Public Health. 2015; 12(3):2984-3001. [DOI:10.3390/ijerph120302984] [PMID] [PMCID]

18. Maslach C, Jackson SE, Leiter MP. MBI: Maslach burnout inventory. Sunnyvale, CA: CPP, Incorporated; 1996.

19. Maslach C, Leiter MP. Understanding the burnout experience: recent research and its implications for psychiatry. World Psychiatry. 2016; 15(2):103-11. [DOI:10.1002/wps.20311] [PMID] [PMCID]

20. Maslach C, Schaufeli WB, Leiter MP. Job burnout. Annual Review of Psychology. 2001; 52(1):397-422. [DOI:10.1146/ annurev.psych.52.1.397] [PMID]

21. Afshani SA, Jahanbakhsh Ganjeh S, Jahanbakhsh Ganjeh S The role of organizational commitment, social support, general health and job satisfaction in predicting burnout among the staff of Social security organization at Kohgiluyeh and Boyer Ahmad. Knowledge \& Research in Applied Psychology. 2017; 18(2):72-81.

22. Cousins R, Mackay CJ, Clarke SD, Kelly C, Kelly PJ, McCaig $\mathrm{RH}$. 'Management standards' work-related stress in the UK: practical development. Work \& Stress. 2004; 18(2):113-36. [DOI:10.1080/02678370410001734322]

23. Azad Me, Gholami FM. Reliability and validity assessment for the HSE job stress questionnaire. International Journal of Behavioral Sciences. 2011; 4(4):291-7.

24. Hashemi NT, Babapur KJ, Bahadori KJ. Role of psychological capital in psychological wellbeing by considering the moderating effects of social capital. Social Psychology Research. 2012; 1(4):123-44.

25. Gashmard R, Bagherzadeh R, Pouladi S, Akaberian S. Burnout and its related demographic factors among the medical staff working in hospitals associated with Bushehr University of Medical Sciences. Puerto Rico Health Sciences Journal. 2015; 34(4):208-14. [PMID]

26. Gholami T, Heidari Pahlavian A, Akbarzadeh $M$, Motamedzade $M$, Heidari Moghadam R. A structural equation modeling study of job stress and musculoskeletal disorders. Iranian Journal of Ergonomics. 2015; 3(3):51-64.

27. Hajloo N. The relationship of staffs'job stress, burnout, and life quality to organizational climate satisfaction at Mohaghegh Ardabili university. Journal of New Approach in Educational Administration. 2012; 3(3):169-83.

28. Jamal M, Baba VV. Job stress and burnout among Canadian managers and nurses: an empirical examination. Canadian Journal of Public Health. 2000; 91(6):454-8. [DOI:10.1007/ BF03404828] [PMID] [PMCID]

29. Rahmani F, Behshid M, Zamanzadeh V, Rahmani F. Relationship between general health, occupational stress and burnout in critical care nurses of Tabriz teaching hospitals. Iran Journal of Nursing. 2010; 23(66):54-63.

30. Shakerinia I, Mohammadpour M. Relationship between job stress and resiliency with occupational burnout among nurses. Journal of Kermanshah University of Medical Sciences. 2010; 14(2):161-9.

31. Watson R, Deary I, Thompson D, Li G. A study of stress and burnout in nursing students in Hong Kong: a questionnaire survey. International Journal of Nursing Studies. 2008; 45(10):1534-42. [DOI:10.1016/j.ijnurstu.2007.11.003] [PMID]

32. Heydari P, Varmazyar S, Hakimi C. Relationship between job stress and musculoskeletal disorders among the personnel of rescue groups: Structural equation modeling. Biotechnology and Health Sciences. 2017; 5(1):e67048.

33. Ahmadpanah M, Torabian S, Dastore K, Jahangard L, Haghighi M. Association of occupational burnout and type of personality in Iranian general practitioners. Work. 2015; 51(2):315-9. [DOI:10.3233/WOR-141903] [PMID]

34. GolMohammadian $M$, Sajjadi SN, Salimi $H$. The role of psychological capital and organizational citizenship 
behavior in predicting job satisfaction of exceptional elementary school's teachers. Exceptional Education Journal. 2016; 3(140):5-12.

35. Luthans F, Avey JB, Avolio BJ, Peterson SJ. The development and resulting performance impact of positive psychological capital. Human Resource Development Quarterly. 2010;
21(1):41-67. [DOI:10.1002/hrdq.20034]

36. Pasha N, Shakerinia I, Abolghasemi A. The relationship of organizational citizenship behaviors, organizational spirituality and social capital with employees' counterproductive behaviors. Psychology. 2017; 4(1):91-111. 